\title{
FATIGUE PROPERTIES AND FRACTURE MECHANISM OF STEEL COATED WITH DIAMOND-LIKE CARBON FILMS
}

\author{
HIROYUKI AKEBONO \\ Department of Mechanical Science and Engineering, Hiroshima University, 1-4-1, Kagami-yama \\ Higashi-Hiroshima city, Hiroshima 739-8527, Japan \\ akebono@hiroshima-u.ac.jp \\ MASAHIKO KATO \\ Department of Mechanical Science and Engineering, Hiroshima University, 1-4-1, Kagami-yama \\ Higashi-Hiroshima city, Hiroshima 739-8527, Japan \\ mkato@hiroshima-u.ac.jp \\ ATSUSHI SUGETA \\ Department of Mechanical Science and Engineering, Hiroshima University, 1-4-1, Kagami-yama \\ Higashi-Hiroshima city, Hiroshima 739-8527, Japan \\ asugeta@hiroshima-u.ac.jp
}

\begin{abstract}
Diamond-like carbon (DLC) films have attracted much attention in many industrial fields because of their excellent tribological properties, high hardness, chemical inertness and biocompatibility. In order to examine the fatigue properties and to clear the fracture mechanism of DLC coated materials, AISI4140 steel coated with DLC films by using unbalanced magnetron sputtering method was prepared and two types of fatigue test were carried out by using a tension and compression testing machine with stress ratio -1 and a bending testing machine with stress ratio -1 with a focused on the fatigue crack behavior in detail. The fracture origin changed from the slip deformation to micro defects at surface whose size didn't affect the fatigue crack initiation behavior in the case of Virgin series because the hard coating like DLC films make the defect sensitivity of coated material higher.. However, DLC series indicated higher fatigue strengths in finite life region and fatigue limit compared with Virgin series. From the continuously observation by using a plastic replicas technique, it is clear that there are no noticeable differences on fatigue crack propagation rate between the Virgin and DLC series, however the fatigue crack initiation of DLC series was delayed significantly by existence of DLC films compared with Virgin series.
\end{abstract}

Keywords: Fatigue; Diamond-like carbon; Fracture mechanism

\section{Introduction}

In recent years, diamond-like carbon (DLC) films have attracted much attention in many industrial fields because of their excellent tribological properties, high hardness, chemical inertness and biocompatibility ${ }^{1-11}$. 
However, there are not enough studies on fatigue characteristics of DLC coated AISI4140 materials which are widely used for machining parts - properties necessary to ensure their long-term safety and reliability ${ }^{12-15}$.

In this study, in order to examine the fatigue properties and to clear the fracture mechanism of DLC coated materials, AISI4140 steel coated with DLC films was prepared and fatigue tests were carried out with a axial loading and a plane bending testing machine.

\section{Specimen and Experiment Method}

The material (substrate) used for this study was a chrome-molybdenum steel AISI4140; Table 1 presents its chemical composition. After machining it into two types of specimens for fatigue tests (Fig. 1), the specimen surfaces were polished by mechanically polishing ( $\mathrm{SiC}$ paper and alumina powder) and then electro-polishing. After the substrate surface was finished into a mirror surface condition, all substrate specimens were coated with DLC films using unbalanced magnetron sputtering (UBMS). Actually, UBMS method can form thin film such as that of DLC using the mechanism that plasma generated near an evaporation source arrives at the work surface, forming a coating by systematically collapsing a magnetic field balance at the sputtering evaporation source where the coating material is evaporated. The structure and the image of cross section by using a Scanning electron microscope(SEM) of DLC coated in this study are presented in Fig. 2 and 3. The thickness of DLC films was $1.2 \mu \mathrm{m}$ onto the tungsten interlayer which was formed to a thickness of $0.8 \mu \mathrm{m}$ to improve the adhesion strength, so the total thickness of the coating used for this study was $2 \mu \mathrm{m}$. For comparing specimens, substrate alone which had not been coated was prepared (Virgin series).

Two types of fatigue test were carried out by using a servo-hydraulic testing machine and an electro-magnetic type bending machine. The condition of fatigue tests were unified in both fatigue tests (sine wave load; frequency: $20 \mathrm{~Hz}$; stress ratio: -1 ). Furthermore, in the case of bending fatigue tests, the fatigue crack was observed continuously by using a plastic replicas technique.

\begin{tabular}{cccccccccc}
\multicolumn{1}{c}{ Table1 Chemical composition of substrate (mass\%) } \\
\hline $\mathrm{C}$ & $\mathrm{Si}$ & $\mathrm{Mn}$ & $\mathrm{P}$ & $\mathrm{S}$ & $\mathrm{Cu}$ & $\mathrm{Ni}$ & $\mathrm{Cr}$ & $\mathrm{Mo}$ & $\mathrm{Fe}$ \\
\hline 0.42 & 0.22 & 0.80 & 0.008 & 0.06 & 0.01 & 0.02 & 1.06 & 0.16 & Bal. \\
\hline
\end{tabular}

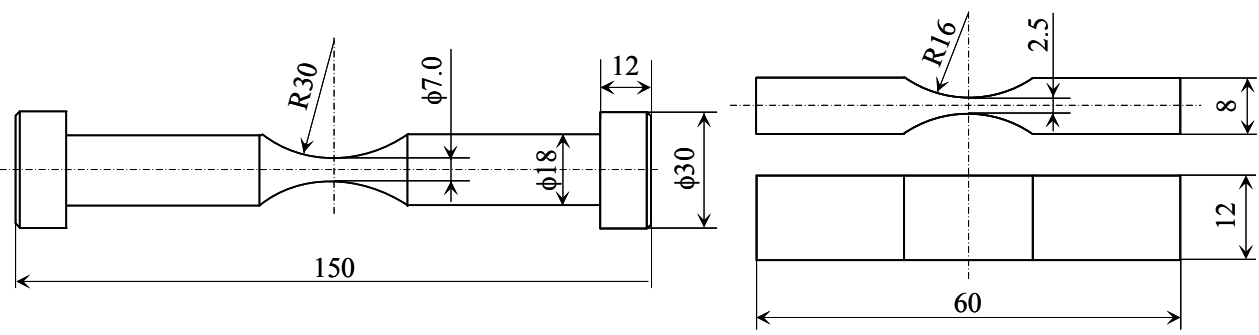

(a) Tension-compression Specimen

(b) Plane bending Specimen

Fig.1 Specimen geometry 


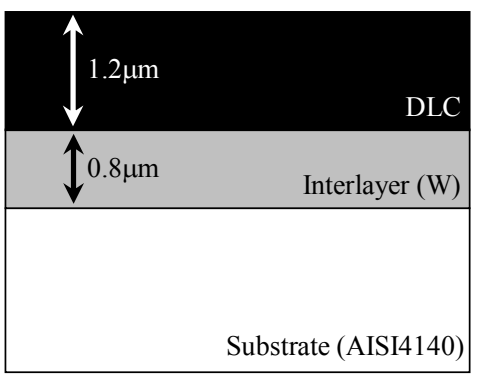

Fig. 2 Structure of DLC films

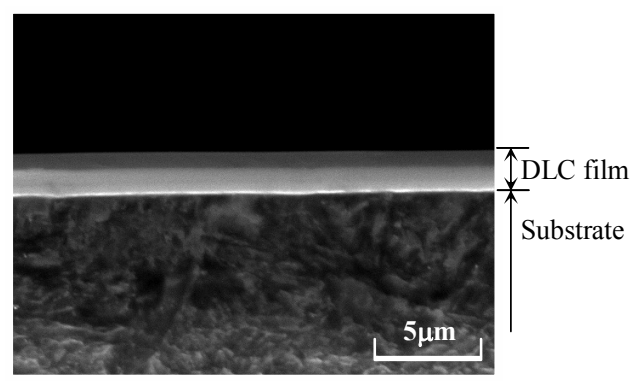

Fig. 3 SEM image of cross section

\section{Experimental Results and Discussion}

Fig. 4 shows the results of the fatigue tests. It is observed that the fatigue strength of DLC series was improved $10 \%$ till $10^{5}$ cycles and $20 \%$ in $10^{7}$ cycles compared with Virgin series. Next, in order to investigate the reason for this, firstly, fracture surfaces were observed by SEM.

Fig. 5 and 6 show typical features of fracture surfaces and fracture origins for Virgin and DLC series. It is observed that the fatigue crack of Virgin series initiated by slip deformation with cyclic loadings and one fracture surface had many fracture origins as shown in figure as arrows, on the other hand it is observed micro defects at the crack initiation site of DLC series and almost DLC series had one fracture origin in one fracture surface as shown in figure as arrows. It was confirmed that these micro defects observed at fracture origin of DLC series were corrosion pits which were formed by the electropolishing before the coating process. In addition, in the case of Virgin series, these micro defects didn't affect the fatigue crack initiation behavior. So, these results suggest that the fracture origin changed from the slip deformation to micro defects because the hard coating like DLC films make the defect sensitivity of coated material higher.

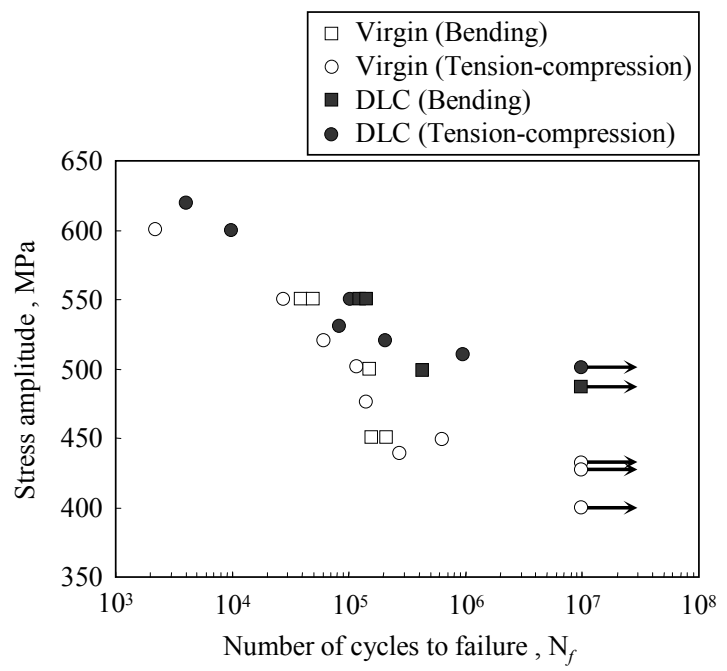

Fig.4 Result of fatigue tests 


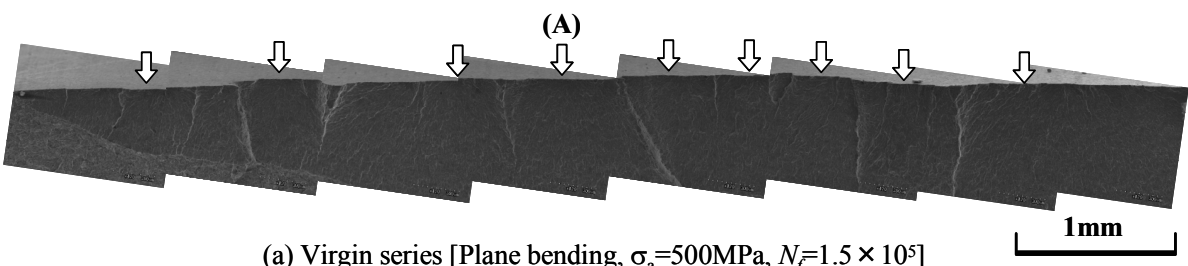

(a) Virgin series [Plane bending, $\left.\sigma_{\mathrm{a}}=500 \mathrm{MPa}, N_{f}=1.5 \times 10^{5}\right]$

(B)

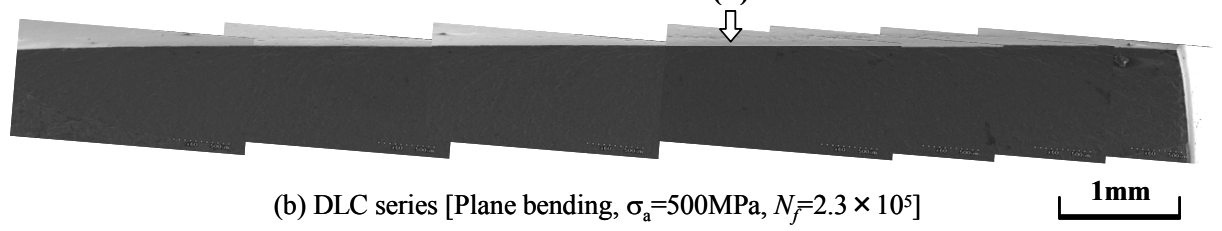

Fig. 5 SEM images of fracture surface

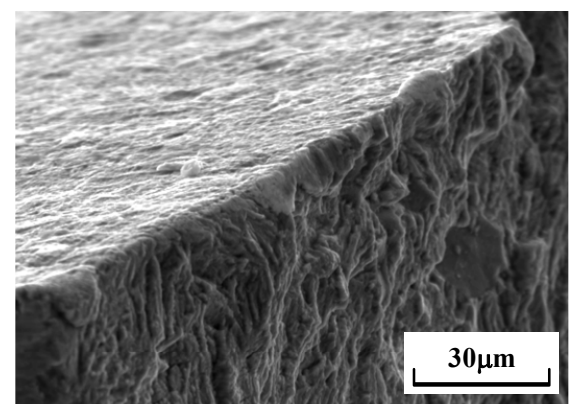

(a) Virgin series (magnified images of (A) in Fig.5)

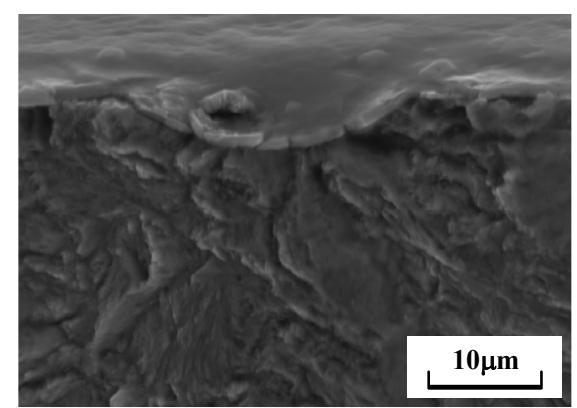

(b) DLC series (magnified images of (B) in Fig.5)

Fig. 6 Magnified images of fracture origin

Next, fatigue cracks of both series were observed by using an optical microscope. Fig. 7 shows typical features of fatigue crack for Virgin and DLC series. From these macroscopic observation, it is observed that the fatigue crack of DLC series propagated linearly in a direction perpendicular to loading direction while that of Virgin series propagated with frequent deflections. Furthermore, fatigue crack tip of both series were observed in detail by using an Atomic Force Microscope (AFM) to examine the fatigue crack more microscopically. From the AFM images shown in Fig. 8, it was confirmed that the fatigue crack of DLC series propagated linearly and that of Virgin series propagated with frequent deflections similar to the macroscopic observation shown in Fig. 7.

Finally, in order to determine the cause of increased fatigue strength by DLC films, fatigue crack behavior of both series was observed continuously by using a plastic replicas technique.

Fig. 9 shows the relationship between the crack length and number of cycle for Virgin and DLC series under the same stress level. It is clear that there are no noticeable 
differences on fatigue crack propagation rate between the Virgin and DLC series despite of the same stress level, however the fatigue crack initiation of DLC series was delayed significantly by existence of DLC films compared with Virgin series. In general, large compressive residual stress in the range of several GPa are present in DLC films ${ }^{16-17}$. So,

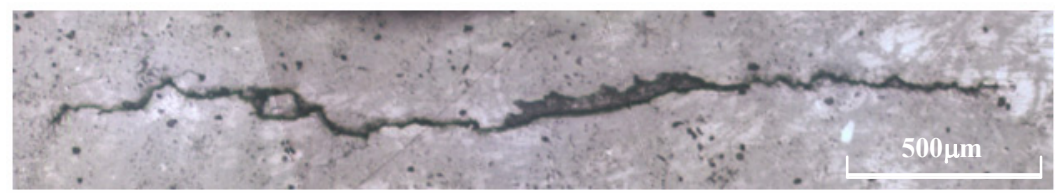

(a) Virgin series [Plane bending, $\sigma_{\mathrm{a}}=500 \mathrm{MPa}$ ]

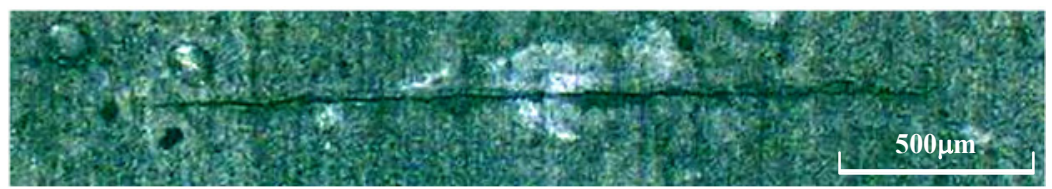

(b) DLC series [Plane bending, $\sigma_{\mathrm{a}}=500 \mathrm{MPa}$ ]

Fig. 7 Fatigue crack observation

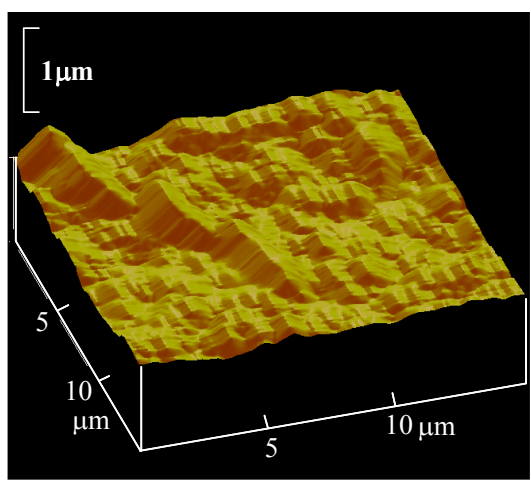

(a) Virgin series

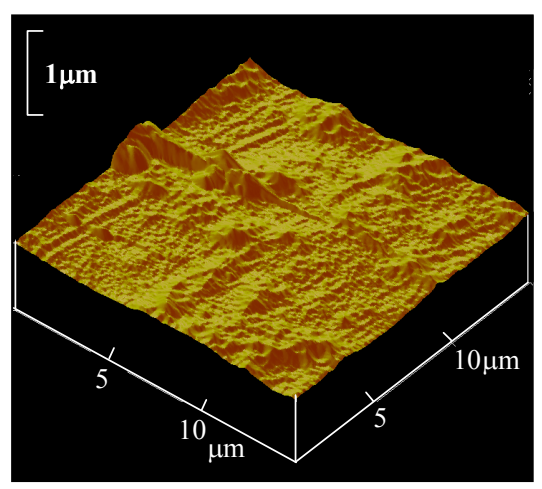

(b) DLC series

Fig. 8 AFM observation of crack tip

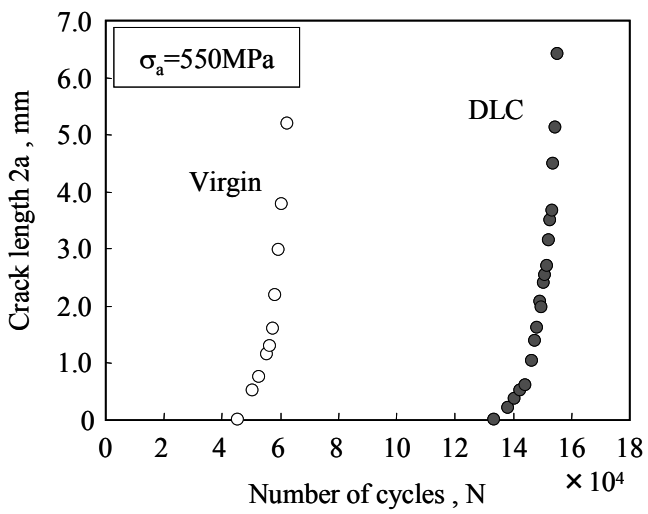

(a) Tension-compression

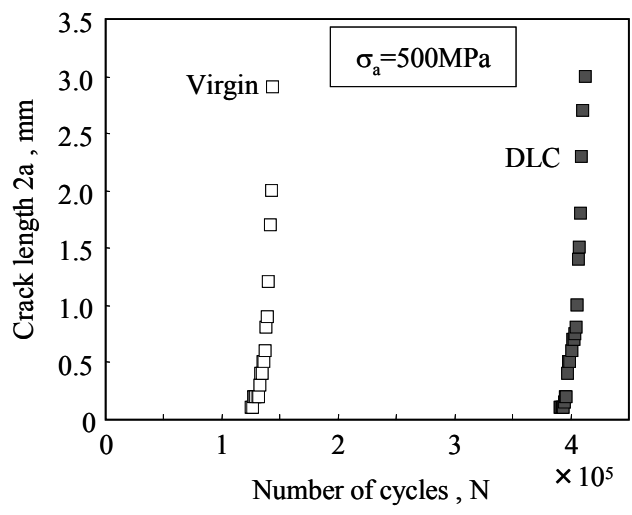

(b) Plane bending

Fig. 9 Relationship between the crack length and number of cycles 
it can be thought that the fatigue crack initiation was delayed by the compressive residual stress in DLC films ,resulting increase of fatigue strength in high cycle fatigue compared with Virgin series.

\section{Conclusions}

In this study, in order to examine the fatigue properties and to clear the fracture mechanism of steel coated diamond-like carbon(DLC) films, AISI4140 steel coated with DLC films was prepared and two types of fatigue test were carried out by using a tension and compression testing machine with stress ratio -1 and a bending testing machine with stress ratio -1 with a focused on the fatigue crack behavior in detail. The conclusions are summarized as follows:

(1) The fatigue strength of DLC series was improved $10 \%$ till $10^{5}$ cycles and $20 \%$ in $10^{7}$ cycles compared with Virgin series.

(2) Fatigue fracture was due to micro defects at surface whose size didn't affect the fatigue crack initiation behavior in the case of without DLC coating. The hard coating like DLC films make the defect sensitivity of coated material higher.

(3)DLC films can suppress the fatigue crack initiation at surface, resulting increase of fatigue strength in high cycle fatigue compared with substrate.

\section{References}

1. M. Kalin and J. Vižintin, Tribology International, 39-10(2006), pp.1060-1067.

2. B. Kržan, F. N. Farkas and J. Vižintin, Tribology International, 42-2(2009), pp.229-235.

3. T.M. Manhabosco and I.L. Muller, Applied Surface Science, 255-7(2009), pp.4082-4086.

4. T. Haque, A. Morina, A. Neville, R. Kapadia and S. Arrowsmith, Wear, 266-1(2009), pp.147157.

5. B. Podgornik, M. Sedlaček and J. Vižintin, Surface and Coatings Technology, 202-4(2007), pp.1062-1066.

6. M. Elmadagli and A.T. Alpas, Wear, 261-7(2006), pp.823-834.

7. Y. Kameyama and J.Komotori, Wear, 263-7(2007), pp.1354-1363.

8. W. Ni, Y.T. Cheng, A.M. Weiner and T.A.Perry, Surface and Coatings Technology, 2016(2006), pp.3229-3234.

9. J. Goldsmith, E. Sutter, J.J. Moore, B. Mishra and M. Crowder, Surface and Coatings Technology, 200-7(2005), pp.2386-2390.

10. A. Pauschitz, S. Kvasnica, R. Jisa, J. Bernardi, T. Koch and M. Roy, Diamond and Related Materials, 17-12(2008). pp.2010-2018.

11. J.H. Wu, S. Karthikeyan, M.L. Falk and D.A. Rigney, Wear, 259-1(2005), pp.744-751.

12. T.Morita, K.Tomita, C.Kagaya, T.Kumakiri and M.Ikenaga, Transactions of the Japan Society of Mechanical Engineers series A, 72-722(2007), pp.1550-1555.

13. H.Okada, Y.Uematsu and K.Tokaji, Procedia Engineering, 2(2010), pp.283-290.

14. L.Rosado, V.K. Jain and H.K. Trivedi, Wear, 212-1(1997), pp.1-6.

15. K.I. Schiffmann, Surface and Coatings Technology, 177(2004), pp. 453-458.

16. J. Deng and M. Braun, Diamond and Related Materials, 5-3(1996), pp.478-482.

17. Y.Oka, M.Kirinuki, Y.Nishimura, K.Azuma, E.Fujiwara and M.Yatsuzuka, Surface and Coatings Technology, 186-1(2004), pp.141-145. 